\title{
Nutrient Interaction: Are Lutein and Omega-3 Docosahexaenoic Acid (DHA) Conditionally Essential and Complementary Nutrients for Visual Function?
}

\section{Mary Harris*}

Professor, Department of Food Science and Human Nutrition, Colorado State University, USA

\section{Editorial}

The traditional approach to nutrition research relies upon the investigation of a single nutrient without consideration of the interaction of nutrients. As with most complex systems, such as visual development, nutrient interactions undoubtedly exist. Many nutrients play a role in the visual process, and the major emphasis has been on the antioxidant nutrients, among them are the xanthophyll pigments, lutein and its stereoisomer, zeaxanthin and the long chain omega-3 fatty acid, Docosahexaenoic Acid (DHA). Lutein and zeaxanthin are the principal components of macular pigment [1]. Since neither lutein nor zeaxanthin can be synthesized in the body, they must be obtained from the diet and may, therefore, be considered conditionally essential nutrients. Lutein plays several important roles in vision. Both lutein and zeaxanthin function by absorbing blue-light, which improves visual acuity and reduces discomfort [1]. Studies have demonstrated that supplementation with lutein increases Macular Pigment Optical Density (MPOD) and improve tolerance to glaring light [2]. Additionally, lutein and zeaxanthin function as antioxidants which may protect macular pigment from oxidative damage induced by light and the high rate of oxidative metabolism in the eye [2]. DHA is the major fatty acid deposited in the retina. It accounts for over $50 \%$ of the fatty acids in the retina and plays a role in maintaining membrane fluidity to promote optimal visual processing [3]. DHA is found in the highest concentrations in the phospholipids of the outer segment disc membranes. The discs are continually being damaged due to the high oxidative activity in the rods and cones and retinal pigment epithelial cells at the interface take up and recycle the DHA. Since the eye is high in reactive oxygen species and DHA is highly susceptible to oxidative damage, it must be protected by the antioxidants in the eye which include lutein, zeaxanthin, vitamin C and vitamin E. Spatially, vitamin $\mathrm{E}$ is the most likely candidate to protect the DHA in the retinal pigment epithelium (RPE) since they both are found in the highest concentrations in the RPE and outer rod segments, but this relationship has not been well studied. A number of studies have demonstrated the effectiveness of lutein and DHA [3-5] supplementation or lutein alone [6-9] on increasing MPOD. Lutein supplementation has been shown to increase macular pigment eccentrically, whereas DHA increases macular pigment density in the central region, where zeaxanthin predominates [4]. Evidence suggests a synergistic effect of combined lutein and DHA supplementation [9]. The loss of macular pigment density is associated with the development of Age Related Macular Degeneration (AMD), the leading cause of blindness in developing countries [1]. Oxidative damage may be a major factor in the development of AMD and may represent a culmination of oxidative damage to the retina throughout a lifetime. The macula is relatively immature at birth and the rapid development of visual function in utero and for the first year after birth parallels the accumulation of pigment in the fovea (the centermost segment of the macula with the highest concentration of photopic visual receptors) [4]. Visual development in the newborn is accompanied by a rapid increase in metabolic activity in the retina [4]. This increase combined with a lack of regulatory blood flow in the newborn, results in hyperoxygenation and places stress upon the antioxidant protective mechanisms [4]. Accumulation of lipofucin, a pigment associated with oxidative damage to the retinal pigment epithelium, shows a rapid increase in the first few years of life, suggesting that damage to the macula may begin in infancy [4]. Conversely, the effect of DHA on lutein concentrations in the eye may be related to the lutein transport into the macula [3]. Lutein and DHA share common transport mechanisms in the blood, with the greatest amount being transported in the apo-e containing High Density Lipoprotein (HDL) fraction [3]. Recently, it has been suggested that apoE containing HDL is the primary source of lipids, lutein and zeaxanthin to the retina [3]. DHA is absorbed from the intestine associated with lyso-phsophytidyl choline, incorporated into chylomicrons and, after degradation to the triglyceride rich particles, taken up by HDL. Therefore, one of the effects of DHA supplementation is an increase in serum HDL [5]. By increasing HDL; lutein levels in the retina may be increased. Although a recent study demonstrated only a slight and non-significant effect of DHA supplementation on serum lutein [10], increased uptake by the retina cannot be ruled out. Currently, no effective intervention for AMD exist sand treatment is aimed at slowing progression of the disease. Trials aimed at the prevention or slowing of macular degeneration have examined both increased MPOD [2,3,6-9,11,12] and various measures of visual function $[2,9,11]$. Although the loss of visual pigment is associated with the development of AMD, the effect of increasing MPOD on slowing the progression of AMD is unclear, many of the differences attributable to the population studied (age, gender, early versus late AMD) adjustment for co-founders including family history, smoking and iris color, as well as methods used to determine MPOD and visual function [13]. Based upon epidemiologic evidence largely supporting the relationship of lutein, zeaxanthin and DHA with AMD [14-17] and the effectiveness of dietary interventions to delay progression of age related eye diseases in the early "Age Related Eye Disease Study" (AREDS) the AREDS2 [18] trial has been initiated to study the interaction of lutein, zeaxanthin and DHA on prevention and treatment of AMD.

\section{References}

1. Davies NP, Morland AB (2004) Macular pigments: their characteristics and putative role. Prog Retin Eye Res 23: 533-559.

2. Stringham JH, Hammond BR (2008) Macular pigment and visual performance under glare conditions. Optom Vis Sci 85: 82-88

3. Johnson EJ, Chung HY, Caldarella SM, Snodderly DM (2008) The influence

*Corresponding author: Mary Harris, Professor, Department of Food Science and Human Nutrition, Colorado State University, USA, E-mail: Mary.Harris@ColoState.EDU

Received January 17, 2013; Accepted January 19, 2013; Published January 26 2013

Citation: Harris M (2013) Nutrient Interaction: Are Lutein and Omega-3 Docosahexaenoic Acid (DHA) Conditionally Essential and Complementary Nutrients for Visual Function? Vitam Trace Elem 2: e119.

Copyright: (c) 2013 Harris M. This is an open-access article distributed under the terms of the Creative Commons Attribution License, which permits unrestricted use, distribution, and reproduction in any medium, provided the original author and source are credited. 
Citation: Harris M (2013) Nutrient Interaction: Are Lutein and Omega-3 Docosahexaenoic Acid (DHA) Conditionally Essential and Complementary Nutrients for Visual Function? Vitam Trace Elem 2: e119.

of supplemental lutein and docosahexaenoic acid on serum, lipoproteins and macular pigmentation. Am J Clin Nutr 87: 1521-1529.

4. Lien EL, Hammond BR (2011) Nutritional Influences on visual development and function. Prog Retin Eye Res 30: 188-203.

5. Chucair AJ, Rotstein NP, SanGiovanni JP, During A, Chew EY et al (2007) Lutein and zeaxanthin protects photoreceptors from apotosis induced by oxidative stress: relation to docosahexaenoic acid. Invest Ophthalmol Vis Sci 48: 6168-5177.

6. Schalch W, Cohn W, Barker FM, Kopcke W, Mellerio J et al (2007) Xanthophyll accumulation in human retina during supplementation with lutein or zeaxanthin: the LUXEA (LUtein Xanthophyll Eye Accumulation) study. Arch Biochem Biophy s458:128-135.

7. Richer S, Davenport J, Lang JC (2007) Last II: Differential temporal responses of macular pigment optical density in patients with atrophic age-related macular degeneration to dietary supplementation with xanthophylls. Optometry 78 : 213-219.

8. Landrum JT, Bone RA, Joa H, Kilburn MD, Moore LL et al (2007) A one year study of the macular pigment: the effect of 140 days of lutein supplement. Exp Eye Res 65: 57-62

9. Nolan JM, Loughman J, Akkali MC, Stack J Scanlon G et al. (2011) The impact of macular pigment augmentation on visual performance in normal subjects: COMPASS. Vision Res 51: 459-469.

10. Huang LL, Coleman HR, Kim J, de Monasterio F, Wong WT et al. (2008) Oral supplementation of lutein/zeaxanthin and omega-3 long chain polyunsaturated fatty acids in persons aged 60 years or older with and without AMD. Invest Ophthalmol Vis Sci 49: 3864-3869.
11. Ma L, Yan SF, Huang YM, Lu XR, Qian F et al (2012) Effect of lutein and zeaxanthin on macular pigment and visual function in patients with early agerelated macular degeneration. Ophthalmology 119: 2290-2297.

12. Delyfer M-N, Buaud B, Korobelnik J-F, Rougier M-B, Schlach W et al. (2012) Effect of lutein and zeaxanthin in macular pigment and visual function in patients with early age-related macular degeneration. Ophthalmology 53: 1204-1210.

13. Ma L, Dou HL, Wu YQ, Huang YB, Xu XR et al. (2012) Lutein and zeaxanthin intake and the risk of age-related macular degeneration: a systematic review and meta-analysis. Br J Nutr 107: 350-359.

14. Ho L, van Leeuwen $R$, Witteman JCM, van Duijn CM, Uiterlinden AG et a (2011) Reducing the genetic risk of age-related macular degeneration with dietary antioxidants, zinc and $\dot{\omega}-3$ fatty acids: the Rotterdam Study. Arch Ophthalmol 129:758-766.

15. Cho E, Hung S, Willett WW, Spiegelman D, Rimm EB et al. (2001) Prospective study of dietary fat and the risk of age-related macular degeneration. Am J Clin Nutr 73: 209-218.

16. Tan JS, Wang JJ, Flood V, Rochtchina E, Smith W et al. (2008) Dietary antioxidants and the long term incidence of age-related macular degeneration :the Blue Mountain Eye Study. Ophthalmology 115: 334-341.

17. San Giovanni JP, Chew EY, Agron E, Clemons TE, Ferris FL et al AREDS Research Group. (2008) The relationship of dietary omega-3 long chain polyunsaturated fatty acid intake with incident age-related macular degeneration: AREDS report no. 23. Arch Ophthalmol 126: 274-1279.

18. Chew EY, Clemons T, Sangiovanni JP, Danis R, Domalpally A et al. (2012) The age-related eye disease study 2 (AREDS2) Report of baseline characteristics. Ophthalmology 119: 2282-2289. 